\title{
A Note on the Fusion of the Lunate and Triquetral Centers
}

\author{
RONALD K. WETHERINGTON \\ Departments of Anthropology and Human Genetics, \\ The University of Michigan, Ann Arbor, Michigan
}

Recently two publications (Dean and Jones, '59; Silverman, '55) have illustrated various stages in the apparent fusion of the lunate and triquetral bones of the wrist and have offered plausible explanations as to its cause. Both papers dealt with its incidence in African children and Silverman showed serial radiograms of a Negro girl from 6 through 8 years of age. Reports of lunate-triquetral fusion indicate it to be more common among Negros than in whites, although no explanation for this has been proposed.

An example of fusion of these carpals was recently found in the course of assessing maturation in 1400 hand films of a control group of Hiroshima children, a project of the Child Health Survey of the Atomic Bomb Casualty Commission. ${ }^{1}$ The single instance is a Japanese boy of $81 / 2$ years (103 months), in whom the two centers have reached the final stage of fusion (fig. 2). So far as we know this is the first report of such fusion in an Oriental. The study is following a cross-sectional, or latitudinal, approach and thus prevents serial radiograms of the stages of fusion. Only left-hand films were taken, making it impossible to ascertain whether the condition in this instance is bilateral.

The film clearly illustrates the absence of any line of union of the two centers, as occurs in Silverman's case ('55; fig. 1C). In none of the illustrations of Dean and Jones ('59) is the process of fusion complete, and they suggest that the line of union "may possibly indicate the formation of a pseudo-arthrosis" (p. 280). Completed fusion without a line of union has been reported in white adults (Curr, '46'47; McConnell, '06-'07), and it is not known at what exact age the two centers completed fusion. In the cases of Curr and McConnell the combined centers have reached their final stages of configuration and size; ours is the first case we found in which fusion is completed in a child, while the maturational status of the combined center is still in an early stage. It seems probable, however, that the line of union in Silverman's figure 1C ( 8 years old) was obliterated shortly thereafter, at about the same age as ours or slightly later.

Dean and Jones also note a tendency of the triquetral to elongate in their cases of "fusion" and suggest a relationship between elongation and the tendency to fuse with the lunate. In our case fusion is so complete that it is difficult to find the original borders. However, we have found several instances in which the triquetral was elongated and rather narrow with no evidence of the tendency of fusion. It seems likely, however, that as the ossification centers approach each other both will tend to lengthen beyond normal dimensions.

Figure 1 illustrates what we consider to be the possible stages of fusion in our case, with the stippled area representing the zone of chondrification prior to ossification. It seems unlikely that accessory centers between the two normal centers could be responsible for this particular case. We found many such accessory centers in our study without any suggestion of fusion. It likewise seems probable that the area between the two centers is joined by a cartilaginous mass sometime prior to overlapping or joining of ossification, but

1 We gratefully acknowledge the financial support in this survey of the U. S. Atomic Energy Commission, the Rockefeller Foundation, the U.S. Public Health Service, and the Association for the Aid of Crippled Children. Gratitude is expressed to Dr. J. V. Neel and D. J. N. Spuhler for their guidance. 
iriq.<smiles>[Te][Te][Te]</smiles><smiles>[Se]=[Se]</smiles>

$1 \quad 2$

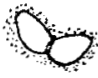

3

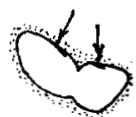

4

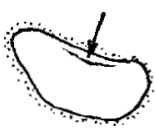

5

Fig. 1 Possible stages of fusion of the lunate and triquetral seen in figure 2. Stippled areas represent zones of chondrification. Arrows indicate volar markings.

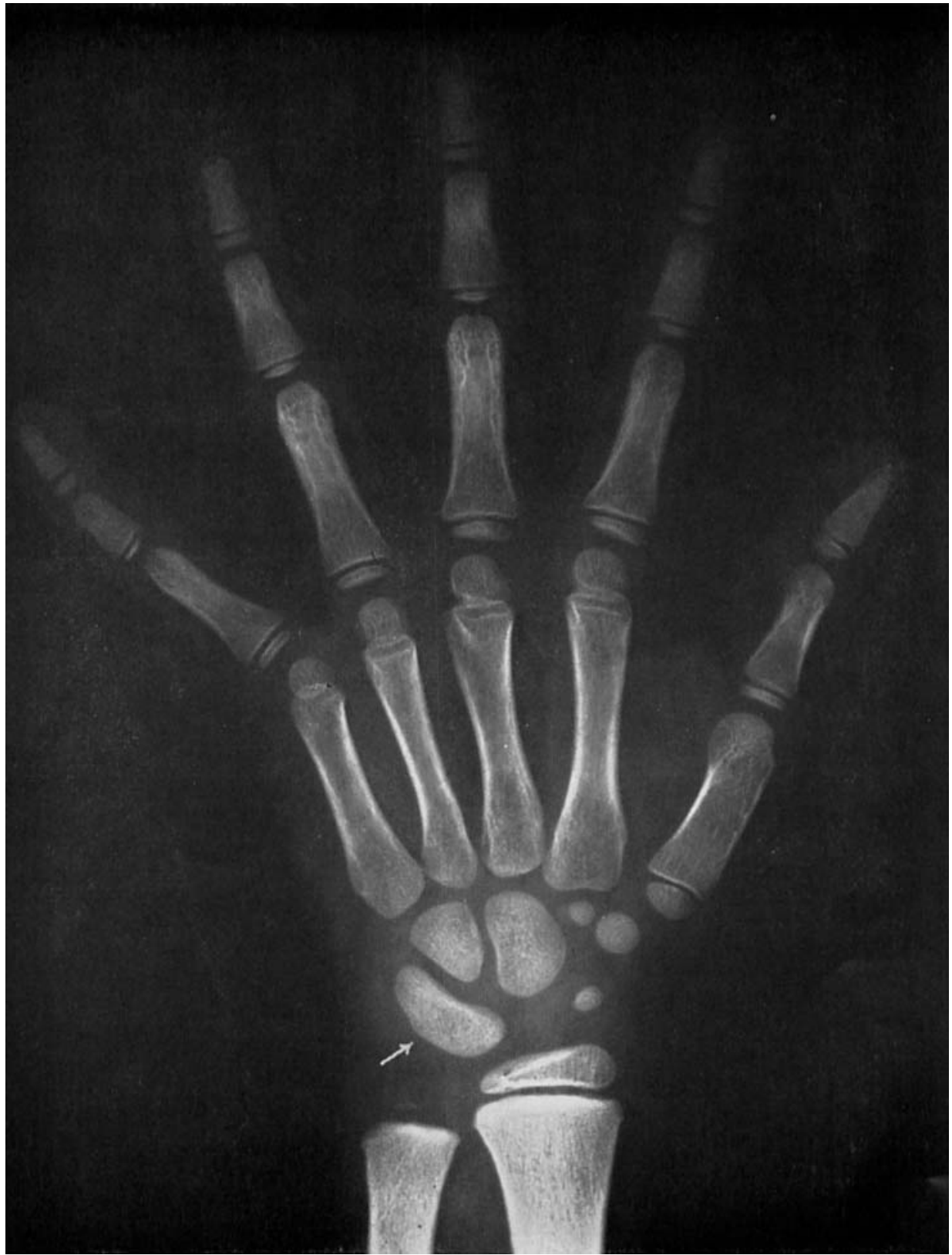

Fig. 2 Fusion of lunate and triquetral centers in Japanese (Hiroshima) boy, aged 103 months. (Courtesy Atomic Bomb Casualty Commission). 
whether this "transarticular" chondrification arises in the fetal stage or after birth is a moot question. We prefer to think that the two cartilaginous masses join just after the two centers of ossification have appeared, or shortly before, as illustrated. Two centers arising in one mass of cartilage is, of course, common, for we see it in ulnar and phalangeal epiphyses, but when this occurs the two centers invariably join to form a single ossific center early in development. In the case of lunate-triquetral fusion, however, the two centers are usually well-developed and often have advanced volar surfaces before joining.

A rudimentary volar marking appears in our film as a dense area on the hamate margin. It is possible that before fusion the two centers were beginning to develop separate articular markings (fig. 1, stage 4).

The hand film shown (fig. 2) was graded by our CHS Method (Wetherington, '61), utilizing maturity points obtained from the indicators of maturity in Greulich and Pyle's Atlas ('59). By this method the child was found to be slightly retarded in skeletal development ( $90 \%$ of normal) for his age, though not significantly so. Normal children in his age group have attained a Total Maturity Index of $50 \%$ (of completed maturity), whereas his Index was $45 \%$. We do not believe this slight retardation to have any association with the Iunate-triquetral fusion.

\section{SUMMARY}

The fusion of lunate and triquetral carpal centers in the wrist of a Japanese boy of $81 / 2$ years was examined. Fusion of the centers was complete and no line of union remained.

It is suggested that the union of the two zones of chondrification preceded the union of the centers and that the centers thus developed, shortly after ossification began, in a single mass of cartilage.

The other centers of the hand had attained a maturational status just below normal, but it is believed that the fusion of the two centers has no effect on the development of the rest of the hand.

\section{LITERATURE CITED}

Curr, J. F. 1946-1947 Congenital fusion of lunate and triquetrum. Brit. J. Surg., 34: 99-100.

Dean, R. F. A., and P. R. M. Jones 1959 Fusion of triquetral and lunate bones shown in serial radiographs. Am. J. Phys. Anthrop., 17: 279288.

Greulich, W. W., and S. I. Pyle 1959 Radiographic Atlas of Skeletal Development of the Hand and Wrist. Stanford University Press, California, 2nd ed.

McConnell, A. A. 1906-1907 A case of fusion of the semilunar and cuneiform bones. $J$. Anat. Physiol., 41: 302-303.

Silverman, F. N. 1955 A note on the os lunatotriquetrum. Am. J. Phys. Anthrop., 13: 143145.

Wetherington, R. K. 1961 An alternate method of assessing skeletal maturity from the hand and wrist. Papers, Mich. Acad. Sci., Arts, and Letters (1960 meeting), 46: 419-433. 